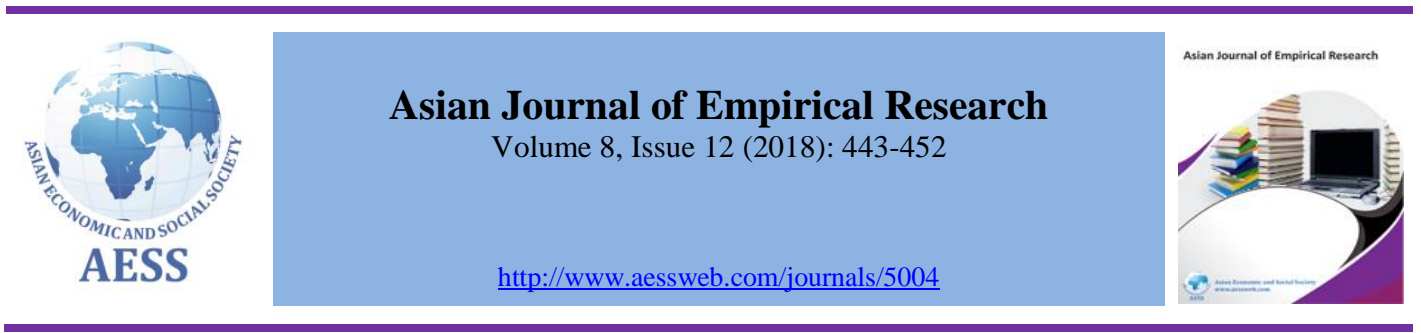

\title{
A study on trust in media and its relationship with interest and exposure of advertising
}

\section{Chi Hong Leung (D) Winslet Ting Yan Chan}

Department of Management and Marketing, The Hong Kong Polytechnic University, Hong Kong, The People's Republic of China

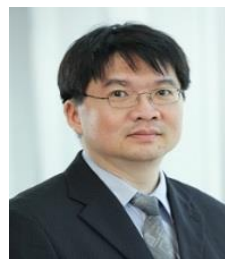

i Corresponding author

\section{ARTICLE HISTORY:}

Received: 30 -Oct-2018

Accepted: 19-Dec-2018

Online available: $11-\mathrm{Jan}-2018$

\section{Keywords:}

Advertising media,

Trust,

Interest,

Consumer attitudes

\begin{abstract}
Consumers receive numerous advertising messages from both online and offline media. Online media are becoming popular because they are convenient and easy to access although users may not trust them as much as the offline media. A total of 109 respondents participated in a survey on their interest and trust in various online and offline media. There are diverse attitudes to different online media. Facebook (as an example of social media) and official webpages (as examples of owned media) are the most interesting and trusted online media while blogs (as examples of informal diary style textual posts) and eBay (as an example of ecommerce platform) are the least interesting and trusted online media. In addition, trust and interest in media are found to be moderately correlated. Thus, consumers feel interested in advertising on trusted media. Besides, the result of the perceived truthiness test with 92 subjects reveals that repeated exposure to product information cannot increase the degree of trust in advertising messages. To choose a suitable medium for advertising is more important than increasing the frequency of advertising.
\end{abstract}

\section{Contribution/ Originality}

To classify media into online and offline ones is too simple for selecting proper advertising media. A survey concludes that people show various degrees of trust and interest in online and offline media and these two attributes are moderately correlated. In addition, a test finds out that increasing exposure to product information cannot contribute to enhancement of trust in advertising message.

DOI: 10.18488/journal.1007/2018.8.12/1007.12.443.452

ISSN (P): 2306-983X, ISSN (E): 2224-4425

How to cite: Chi Hong Leung and Winslet Ting Yan Chan (2018). A study on trust in media and its relationship with interest and exposure of advertising. Asian Journal of Empirical Research, 8(12), 443-452.

(C) 2018 Asian Economic and Social Society. All rights reserved 


\section{INTRODUCTION}

Trust is a generic concept and considered essential for human relationships. Trust is defined in several ways operationally and theoretically in various areas including politics (Fukuyama, 1995), economics (Williamson, 1993), organizational behaviors (Rousseau et al., 1998) and psychology (Couch and Jones, 1997; Tsfati and Cappella, 2005). There was growing interest of the concept of trust (Hardin, 2002) in the area of social sciences since the 1990s. Trust is a significant foundation for balanced social relationships and social order for people to perform properly either as a group or individually (Lewis and Weigert, 1985). Relying on the level of trust that people have in political systems, organizations and individuals, trust can enable people to predict and plan reasonably about probable future events (Barber, 1983; Zucker, 1986). For example, if consumers think a company is trustworthy, they will consider products offered by the company. Oppositely, if people lose trust in the company because of inferior quality of products and bad experience, they might consider other companies that can be trusted in the long run.

Trust is vital to research on advertising because of a steady trend for people to distrust advertising (Calfee and Ringold, 1994). Today a typical consumer is exposed to 4,000 to 10,000 brand message daily. The images of media have impacts on consumers' perception of the business brands (Asli, 2017). The primary purpose of advertising is to inform people of companies' offerings. Important for fulfilling of this purpose is that customers have to trust advertising effectually as a source of information. Trust should be an established antecedent of persuasion (Calfee and Ringold, 1994). In addition, trust is correlated with accepting information and liking (Petty and Cacioppo, 1981). Trust is also essential to relationships between sellers and consumers (Menon et al., 2004).

From the perspective of advertising, trust is conceptualized and measured in four forms: credibility of source, advertising, content and media (Haley, 1996; Huh et al., 2004). Source credibility refers to credibility of the product information source. It is found that trustworthiness, attractiveness and expertise of advertisers and endorsers are the major dimensions. Advertising credibility refers to perceived believability and truthfulness of advertising generally. This is formed by three constructs: advertiser and advertising credibility and ad claim discrepancy. Content credibility is about whether ad claims are true and believable. Media credibility is about the advertising delivery channels. It is found that this credibility perception is different across various media and consumer demographics. Recently, it is found that the offline (traditional) media are more trusted by people (Nanji, 2017; Statista, 2016; Tam, 2015) although the online media are becoming more convenient for consumers to receive commercial information.

Most companies still rely on traditional media. Now with the advance in technologies and online media, advertising had undergone a remarkable change. Online media provide several benefits to consumers like convenient access to information, interactive and immediate action, and comparison among various companies' information. However, there is a lot of concern over trust in the online media. Unlike traditional media, the online environment such as social media allows people to upload and share the information without inspection of its validity. This paper studied the differences in trust and interest among various major advertising media both offline and online, and the relationship between them in advertising media. In addition, the study evaluated if exposure to media could influence the perceived truthiness of product information.

\section{LITERATURE REVIEW}

The concept of trust is studied in several subjects. Trust is an important component and a necessary aspect of social interaction for dealing with less intractable matters (Gambetta, 1988). Psychologists reveal that between a trustee and a trustor, trust occurs and involves the notion of predictability and motivational relevance (Mayer et al., 1995). Economists regard trust as partially a function of policies 
and institutions (Berggren and Jordahl, 2006). Politicians consider trust as a fundamental assessment toward the governmental agencies (Hetherington, 1998).

Sociologists think trust is a multidimensional construct (Zucker, 1986) and a foundation for social institutions (Barber, 1983) and interpersonal relationships (Granovetter, 1985). Trust is perceived as a collective unit property instead of separated persons (Lewis and Weigert, 1985). Trust is applied to the relationships among individuals in society. It occurs when people in a social system act based on the anticipated future composed by the presence of each other (Barber, 1983). The significance of trust is dependent on the complexity and nature of the interaction with each other. Thus, the greater the dependence on each other, the greater the need to trust.

Sociologist theorized that to decide to trust involves assessing to what extent one fulfills a particular expectancy in the future (Vanacker and Belmas, 2009). To consume an expected subject may be based on trust. An individual has to give trust in an active manner and the trusted side actively accepts, acknowledges and addresses that trust. For instance, the users have to decide to trust which information source of media, according to the anticipation that the information source can meet their requirements in the future. Trust in the media leads to consumption of information from the media and mistrust could turn people away (Lee, 2010). Trust is important to understand several human behaviors since it interferes in most aspects of social lifespan (Tsfati and Capella, 2005). Trust is a situation between not knowing and knowing (Simmel, 1968). It is because trust is involved only when one is not informed of all details of an issue to make a decision rationally. If one trusts a politician to rule and act properly, he castes a vote for the politician. If one trusts a doctor to offer suitable treatment, he seeks medical advice and assistance from the same doctor again. Similarly, trust in media affects how people use media.

Trust is related to the area of communication with media. Trust is an important factor influencing whether the public continues to embrace the media. Mistrust of media may lead to non-consumption and inattention (Lee, 2010). When people do not trust information from the media, it is less likely that they will pay attention to them (Johnson and Kaye, 1998). There is the decline of trust in public sectors although trust is considered an important variable in media consumption (Cook and Gronke, 2001; Holmes, 2009). Since the 1970s, public trust in main American institutions has been declining (Paxton, 2005; Smith, 2008).

When marketers create and lunch a successful advertising campaign, it is necessary to use the best media for their products. It is essential to assess consumer trust and understand how people respond to advertisements in various media especially when people find advertising untruthful now. Thus, marketers have to measure in which media it would be appropriate to launch advertising campaigns. Various media may appeal to people in different manners. The following were the research questions in this study.

- Is trust different among various advertising media?

- In what media is advertising least/most trusted?

- Does interest in advertising relate to trust in different advertising media?

- Does exposure to media affect the perceived truthiness of product information?

In particular, the study compared the differences in trust and interest between online and offline advertising media People get used to receiving more and more advertising messages from the online media. But does it imply that they trust online media more than offline ones? Young people are the major users and consumers in the online environment and, thus, they were invited to participate in the survey on trust and interest in various media, and the test on the perceived truthiness of product information after exposure to these media. 


\section{METHODOLOGY}

The research instrument used in this study consisted of the following two components.

- a survey on interest and trust in advertising media, and

- a perceived truthiness test

There were two sections in the survey. The first section was to collect data about respondents' interest in the following eight media. The first four were the online media while the others were the traditional and offline media.

- Online media

1. Official webpage

2. Facebook

3. Blog

4. eBay

- Offline media

5. Print newspaper

6. Outdoor billboard

7. Print leaflet

8. Print magazine

The four online media above have various features. Official webpages are the major owned media of companies. A company may provide information on the webpages for content marketing and attracting consumers to pay attention to their products. Facebook is an example of popular social media that can be accessed by online users to share their content with others. Now marketers may take advantages of social media to communicate with consumers and promote their products. Blogs are mainly dominated by particular authors, like KOL (key opinion leaders), who offer their content on various topics in a diary style. eBay is an e-commerce platform on which online buyers and sellers meet and complete transactions. Thus, there is a lot of information about the products available on eBay and in addition there are reviews and comments written by users who purchased products before.

The other four media mentioned above are offline ones. They are typical channels for traditional advertising in print and outdoor media. The reason for selecting them was that they could be presented as still pictures in the survey conveniently and practically. It becomes inconvenient and impractical to present a clip of TV commercial or radio advertising in a survey.

For each of these eight media, the following five imaginary (or fake) products were presented in photographs showing such product advertising in these media.

- Coca-Cola in a green can

- iPlay (that looks like an Apple's product)

- Starbucks hot chocolate machine for the personal usage at home

- Nike mobile phone

- McDonalds' pop-corn

Thus, a total of 40 photographs (5 products $\times 8$ media) were presented in this section of the survey. In Figure 1, there are two examples: McDonald's pop-corn on the official webpage and iPlay on the outdoor billboard. For each of these photographs, respondents indicated their interest in the media although they were not informed that these products were fake. 


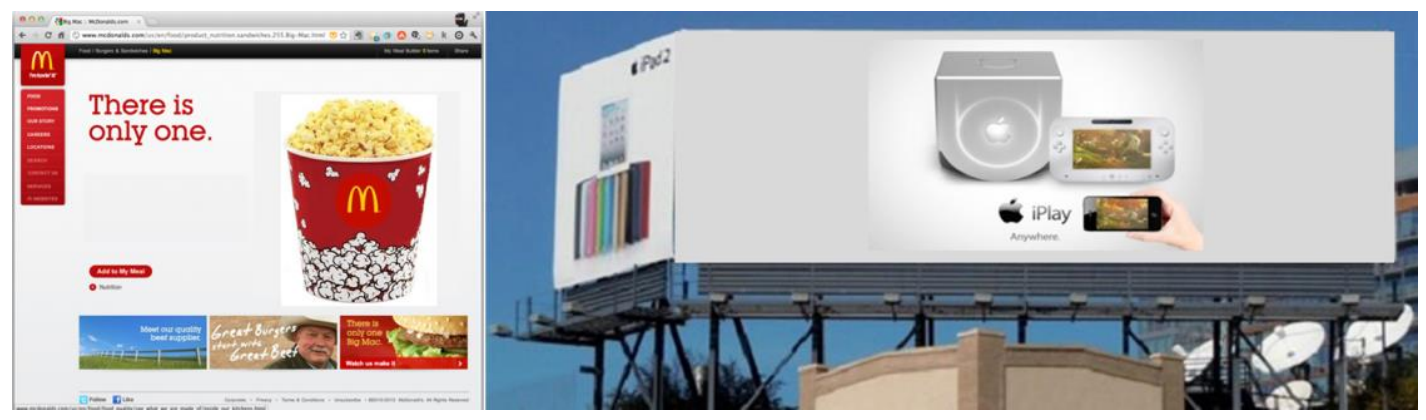

Figure 1: Photographs presented in the first section of the survey (the left is McDonald's popcorn on the official webpage and the right is iPlay on the outdoor billboard)

There were two reasons why fake products were used in the survey. First, the fake products were obviously not seen by the respondents before. Thus, the products themselves did not influence the responses that should reflect only respondents' interest in media. Second, after presenting fake product advertising to respondents, it was possible to test if respondents would really believe that they were real products in the perceived truthiness test (i.e., the second component of the research instrument used in this study).

In the second section of the survey, respondents would be asked to rank the level of trust in these media. Each respondent ranked these eight media from $8=$ most trusted to $1=$ least trusted. These two sections of the survey could provide data to find out if there was any correlation between interest and trust in these advertising media.

After finishing the survey, the respondents performed the perceived truthiness test in which there were five questions regarding the five fake products presented in the survey respectively. Each question presented three products (one fake and two real products). For example, in a question (see Figure 2), iPlay and two real products from Apple were presented. The criterion for selecting the real products was that they were uncommon for the majority of users. These three products (real or fake) were also described to be produced by the same company. The respondents were asked to select a fake one in each question. The purpose of this test was to find out if exposure to the media (in the survey) could affect the perceived truthiness of product information.

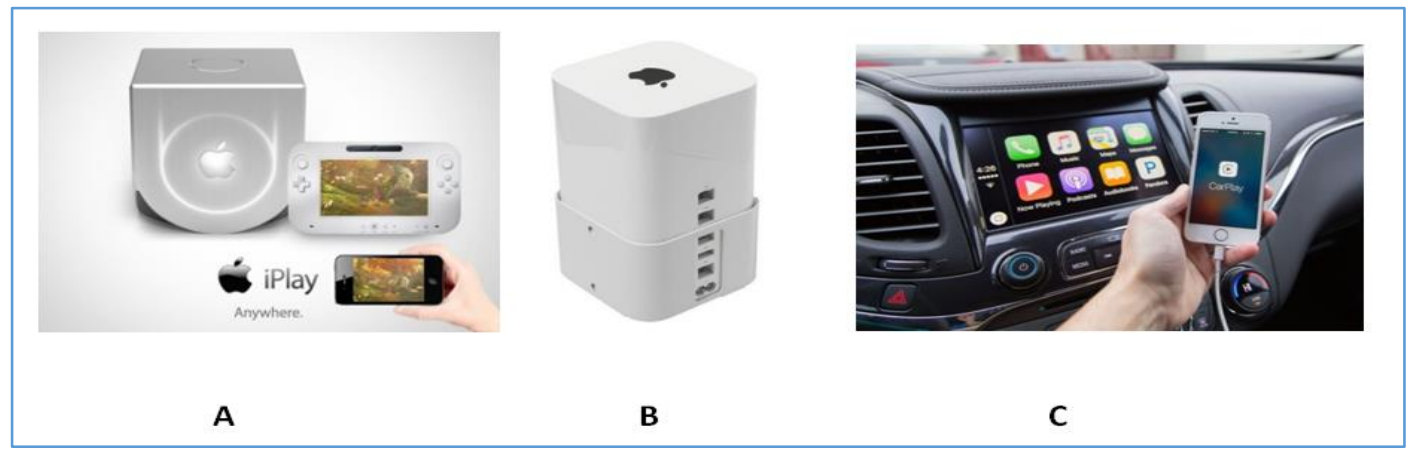

Figure 2: An example of a question in the perceived truthiness test

\section{RESULTS AND ANALYSIS}

A total of 109 respondents who were university students participated in the survey and the perceived truthiness test. In the survey, they first indicated the degree of their interest in 40 photographs that were combinations of the five products shown in the eight media. Likert scale was used in this survey 
( 1 = very uninteresting, $2=$ uninteresting, $3=$ neutral, $4=$ interesting, $5=$ very interesting). For each respondent, an overall interest score of each medium was calculated based on the interest scores of five products shown in the same medium. Thus, each respondent got eight overall interest scores of eight media respectively. The averages of the overall interest scores are shown in Table 1.

Table 1: Averages of the overall interest scores

\begin{tabular}{lccccccc}
\hline $\begin{array}{l}\text { Official } \\
\text { Webpage }\end{array}$ & Facebook & Blog & eBay & Print & $\begin{array}{c}\text { Offline (traditional) media } \\
\text { Outdoor }\end{array}$ & $\begin{array}{c}\text { Print } \\
\text { newspaper }\end{array}$ & Prillboard \\
leaflet & magazine \\
\hline 3.405 & 3.378 & 2.908 & 2.533 & 2.938 & 3.836 & 3.259 & 3.103 \\
\hline
\end{tabular}

It was found that the score of the outdoor billboard was the highest among all the media. It is suggested that billboard advertising usually creates the obvious visual impacts on prospects. Consumers remember pictures more easily than textual blocks of information. When the visuals are interesting, consumers pay attention to what advertisers like to convey. Limited information is usually a disadvantage of billboard advertising but it seems to be more suitable in today's environment in which there is too much information overloaded in our daily lives.

For detailed investigation, ANOVA was performed to compare the overall interest scores of the all eight media. Tukey's HSD Post Hoc Test was included in ANOVA to show the homogeneous subsets in Table 2. The outdoor billboard (mean $=3.8365$ in Subset 5) was the most interesting while eBay (mean $=2.5335$ in Subset 1) was the least interesting. Between these two extremes, there were three more subsets. Facebook and the official webpage were in the subset of the second highest score (Subset 4) while the blog and print newspaper were in the subset of the second lowest score (Subset 2). On the whole, the respondents showed the diverse degrees of interest in online media. They were interested in the official webpage and Facebook but not so in eBay and the blog.

Table 2: Tukey's HSD post hoc test showing the homogeneous subsets of interest scores

\begin{tabular}{|c|c|c|c|c|c|c|}
\hline \multicolumn{7}{|c|}{$\begin{array}{c}\text { Overall interest scores } \\
\text { Tukey HSD using Uses Harmonic Mean Sample Size = } 109\end{array}$} \\
\hline \multirow{2}{*}{ Advertising media } & \multirow{2}{*}{$\mathbf{N}$} & \multicolumn{2}{|c|}{ Subset for alpha $=0.05$} & \multirow[b]{2}{*}{3} & \multirow[b]{2}{*}{4} & \multirow[b]{2}{*}{5} \\
\hline & & 1 & 2 & & & \\
\hline eBay & 109 & 2.533 & & & & \\
\hline Blog & 109 & & 2.908 & & & \\
\hline Print newspaper & 109 & & 2.938 & & & \\
\hline Print magazine & 109 & & 3.103 & 3.103 & & \\
\hline Print leaflet & 109 & & & 3.259 & 3.259 & \\
\hline Facebook & 109 & & & & 3.378 & \\
\hline Official webpage & 109 & & & & 3.405 & \\
\hline Outdoor billboard & 109 & & & & & 3.836 \\
\hline Significance & & 1.000 & 0.279 & .573 & .663 & 1.000 \\
\hline In homogeneous sul & , mec & for groups & isplayed. & & & \\
\hline
\end{tabular}

The survey also collected respondents' trust in the eight media. Each respondent ranked these eight media from $8=$ most trusted to $1=$ least trusted. The average ranks of trust are shown in Table 3 .

Table 3: Average ranks of trust in media

\begin{tabular}{lccccccc}
\hline $\begin{array}{l}\text { Official } \\
\text { Webpage }\end{array}$ & Facebook & Blog & eBay & Print & Offline (traditional) media \\
Outdoor & Print & Print \\
newspaper & billboard & leaflet & magazine \\
\hline 5.407 & 6.039 & 3.941 & 3.156 & 3.333 & 6.019 & 4.362 & 3.794 \\
\hline
\end{tabular}


For detailed investigation, ANOVA was performed to compare the trust rank of the all eight media. Tukey's HSD Post Hoc Test was included in ANOVA to show the homogeneous subsets in Table 4. The outdoor billboard, official webpage and Facebook in Subset 3 were the most trusted while eBay and blogs were the least trusted in Subset 1. On the whole, the respondents showed the diverse degrees of trust in online media. They trusted the official webpage and Facebook but not so in eBay and blogs. This result is comparable to respondents' interest in online media. Thus, it is worthy investigating the correlation between trust and interest in these media.

Table 4: Tukey's HSD post hoc test showing the homogeneous subsets of trust ranks

\begin{tabular}{|c|c|c|c|c|}
\hline \multirow{3}{*}{ Advertising media } & \multicolumn{4}{|c|}{$\begin{array}{c}\text { Trust rank } \\
\text { Tukey HSD using harmonic mean sample size }=109\end{array}$} \\
\hline & $\mathbf{N}$ & & for alpl & \multirow[b]{2}{*}{3} \\
\hline & $\mathbf{N}$ & 1 & 2 & \\
\hline$\overline{\text { eBay }}$ & 109 & 3.156 & & \\
\hline Blog & 109 & 3.333 & & \\
\hline Print newspaper & 109 & 3.794 & 3.794 & \\
\hline Print magazine & 109 & 3.941 & 3.941 & \\
\hline Print leaflet & 109 & & 4.362 & \\
\hline Facebook & 109 & & & 5.407 \\
\hline Official webpage & 109 & & & 6.019 \\
\hline Outdoor billboard & 109 & & & 6.039 \\
\hline Significance & & 0.103 & 0.475 & 0.333 \\
\hline In homogeneous su & for & displa & & \\
\hline
\end{tabular}

The correlations between trust and interest in advertising media are presented in Table 5. It was found that there was a moderate correlation between respondents' interest and interest in media because all the figures of correlation coefficient were about 0.5 . It is concluded that when one shows trust in an advertising medium, to a certain extent he/she is interested in the information presented in the same medium.

Table 5: Correlation between trust and interest in advertising media

Correlation between trust and interest among ....

All online media (official webpage, Facebook, Blog \& eBay)

All offline media (print newspaper, outdoor billboard, print

Leaflet \& print magazine)

All eight media
Pearson correlation coefficient

0.5227

0.5401

0.5108

In the perceived truthiness test, there were five questions. There were three products in each question presented to respondents who selected the one perceived to be fake. The total number of respondents participating in this test and providing valid responses was 92 . Thus, the total number responses was $460(=92 \times 5)$. The results are shown in Table 6 .

Table 6: Frequency of products selected in the perceived truthiness test

\begin{tabular}{lcccc}
\hline & $\begin{array}{c}\text { Fake product } \\
\text { selected correctly }\end{array}$ & $\begin{array}{c}\text { Real product \#1 } \\
\text { selected incorrectly }\end{array}$ & $\begin{array}{c}\text { Real product \#2 } \\
\text { selected incorrectly }\end{array}$ & Total \\
\hline Frequency & 178 & 168 & 119 & 460 \\
Percentage & $37.61 \%$ & $36.52 \%$ & $25.87 \%$ & $100.00 \%$ \\
\hline
\end{tabular}

If each product (fake or real) is selected in a random manner, the expected frequency of each should be $33.33 \%$. The Chi-Square test was performed to conclude that the responses in the test did not follow this assumption of the equal chance $(\mathrm{p}=0.0374$ at alpha $=0.05)$. The fake products were actually 
selected with a higher percentage $(37.61 \%>33.33 \%)$ and, thus, exposure of fake products in various media could not enhance the level of trust in these products.

To choose a medium, a marketer has to decide the frequency required to achieve the advertising objective. The frequency is the number of times the target consumers are exposed to the message in a particular period. It is anticipated that people may only take the action (e.g., purchasing a product or requesting for further information) after being exposed to advertising for several times. Theoretically to increase the frequency of advertising is useful for attaining the promotional goals. However, the perceived truthiness test revealed that trust could not be enhanced simply by increasing the frequency of exposure to the product information.

\section{CONCLUSION}

Nowadays, people are receiving a lot of commercial information from various online and offline media. In general, consumers become overloaded with such information in a daily manner. Under such a situation, people may have formed certain attitudes to these advertising media. It is hypothesized that consumers may be interested in advertising in media that they trust. This is a kind of selective filtering of commercial information based on advertising media. For example, when people distrust the information in the online blog, they may not like and pay attention to advertising there.

This paper studied consumers' interest and interest in advertising media and their relationship. The survey revealed the following important findings. First, it is too straightforward to describe consumers showing preference for online or offline media. The respondents were interested in the official webpage and Facebook but not so in the blog and eBay although they were all online media. Second, respondents also showed different levels of trust in advertising media. Again, the respondents trusted in the official webpage and Facebook but not so in the blog and eBay. Third, there was moderate correlation between interest and trust in advertising media. This implies that consumers are more interested in advertising in the trusted media, compared with those in the distrusted ones. The perceived truthiness test showed that more exposure to a fake product (or fake information) in media could not increase the trust level of commercial information. On the whole, it is concluded that trusted media should be selected cautiously because there is correlation between trust and interest in advertising media. In addition, to select a proper medium for advertising is more important than the frequency of advertising in the medium.

\section{Funding: This study received no specific financial support.}

Competing Interests: The authors declared that they have no conflict of interests.

Contributors/Acknowledgement: All authors participated equally in designing and estimation of current research.

Views and opinions expressed in this study are the views and opinions of the authors, Asian Journal of Empirical Research shall not be responsible or answerable for any loss, damage or liability etc. caused in relation to/arising out of the use of the content.

\section{References}

Asli, A. (2017). Consumers increasingly distrust brands and advertising. Here is why, Accessed October 15, 2018. https://business.yocale.com/consumers-increasingly-distrust-brands-andadvertising-here-is-why/.

Barber, B. (1983). The logic and limits of trust. In Lewis, D., \& Weigert, A. (Eds.), Social Forces, 63(4), 967-985. Rutgers University Press. view at Google scholar / view at publisher

Berggren, N., \& Jordahl, H. (2006). Free to trust: Economic freedom and social capital. KYKLOS, 29(2), 141-169. view at Google scholar / view at publisher

Calfee, J. E., \& Ringold, D. J. (1994). The 70\% majority: Enduring consumer beliefs about advertising. Journal of Public Policy \& Marketing, 13, 228-238. view at Google scholar 
Cook, T, E., \& Gronke, W. (2001). The dimensions of institutional trust: How distinct is public confidence in the media? Paper presented at the annual meeting of the Midwest Political Science Association, Chicago, IL. http://people.reed.edu/ gronkep/docs/MIDW2001.pdf.

Couch, L., \& Jones, W. H. (1997). Trust and betrayal: The psychology of getting along and getting ahead. Handbook of Personality Psychology. San Diego: Academic Press. view at Google scholar

Fukuyama, F. (1995). Trust: Social virtues and the creation of prosperity. New York: Free Press. view at Google scholar / view at publisher

Gambetta, D. (1988). Trust: Making and breaking cooperative relations. New York: Basil Blackwell. view at Google scholar / view at publisher

Granovetter, M. S. (1985). Economic action and social structure. American Journal of Sociology, 91, 85-112. view at Google scholar

Haley, E. (1996). Exploring the construct of organization as source: Consumers' understanding of organizational sponsorship of advocacy advertising. Journal of Advertising, 25(2), 19-35. view at Google scholar / view at publisher

Hardin, R. (2002). Trust and trustworthiness. New York: Russell Sage. view at Google scholar / view at publisher

Hetherington, M. J. (1998). The political relevance of political trust. The American Political Science Review, 92(4), 791-808. view at Google scholar

Holmes, P. (2009). Trust in American institutions continues its decline. http://www.holmesreport.com/opinioninfo/8020/Trust-in-American-Institutions-ContinuesIts-Decline.aspx.

Huh, J., DeLorme, D. E., \& Reid, L. N. (2004). Media credibility and informativeness of direct-toconsumer prescription drug advertising. Health Marketing Quarterly, 21(3), 27-61. view at Google scholar / view at publisher

Johnson, T. J. \& Kaye, B. K. (1998). Cruising is believing? Comparing Internet and traditional sources on media credibility measures. Journalism and Mass Communication Quarterly, 75(2), 325340. view at Google scholar / view at publisher

Lee, T. T. (2010). Why they don't trust the media: An examination of factors predicting trust. American Behavioral Scientist, 54(1), 8-21. view at Google scholar / view at publisher

Lewis, J., \& Weigert, A. (1985). Trust as a social reality. Social Forces, 63(4), 967-985. view at Google scholar / view at publisher

Mayer, R. C., Davis, J. H., \& Schoorman, F. D. (1995). An integrative model of organizational trust. The Academy of Management Review, 20(3), 709-734. view at Google scholar

Menon, A. M., Deshpande, A. D., Zinkhan, G. M., \& Perri, M. III. (2004). A Model of assessing the effectiveness of direct-consumer-advertising: Integration of concepts and measures from marketing and healthcare. International Journal of Advertising, 23(1), 91-118. view at Google scholar / view at publisher

Nanji, A. (2017). The advertising media that consumers trust most. Accessed October 222018. https://www.marketingprofs.com/charts/2017/33294/the-advertising-mediums-thatconsumers-trust-most.

Paxton, P. (2005). Trust in decline? Contexts, 4(1), 40-46. view at Google scholar

Petty, R. E., \& Cacioppo, J. T. (1981). Attitudes and persuasion: classic and contemporary approaches. Dubuque, IA. Wm. C. Brown Publishing Company, 64-65. view at Google scholar

Rousseau, D. M., Sitkin, S. B., Burt, R. S., \& Camerer, C. (1998). Not so different after all: A crossdiscipline view of trust. Academy of Management Review, 23(3), 393-404. view at Google scholar / view at publisher

Simmel, G. (1968). Sociology: studies on the forms of socialization. $5^{\text {th }}$ ed. Duncker \& Humbolt, Berlin. view at Google scholar

Smith, J. A. (2008). America's trust fall. Retrieved from

http://greatergood.berkeley.edu/article/item/americas_trust_fall/. 
Statista. (2016). In which, if any, of the following places are you most likely to find advertising that you trust? Accessed October 22 2018. https://www.statista.com/statistics/272668/consumertrust-in-different-types-of-advertising-in-the-united-kingdom/.

Tam, I. (2015). Trust in traditional advertising still strong: Nielsen survey. Accessed October 222018. https://www.marketing-interactive.com/trust-traditional-advertising-still-strong-nielsensurvey/

Tsfati, Y., \& Cappella, J. N. (2005). Why do people watch news they do not trust? The need for cognition as a moderator in the association between news media skepticism and exposure. Media Psychology, 7(3), 251-271. view at Google scholar / view at publisher

Vanacker, B., \& Belmas, G. (2009). Trust and the economics of news. Journal of Mass Media Ethics, 24, 110-126. view at Google scholar

Williamson, O. E. (1993). Calculativeness, trust, and economic organization. Journal of Law and Economics, 36, 453-486. view at Google scholar / view at publisher

Zucker, L. G. (1986). Production of trust: Institutional sources of economic structure 1840-1920. Research in Organizational Behavior, 8, 53-111. view at Google scholar 